\title{
KESENIAN GAMBANG SEMARANG DALAM KELOMPOK PAHAT ETHNIC SEMARANG
}

\section{THE ARTS OF GAMBANG SEMARANG IN PAHAT ETHNIC GROUP SEMARANG}

\author{
Dadang Dwi Septiyan ${ }^{1}$ \\ ${ }^{1}$ Pendidikan Seni Drama, Tari, dan Musik - Universitas Sultan Ageng Tirtayasa \\ ${ }^{(*)} \bowtie$ (e-mail) dadang.vivaldi@untirta.ac.id¹
}

\begin{abstract}
Abstrak
Tujuan dari penelitian ini adalah untuk mengetahui keberadaan Musik Gambang Semarang di Kota Semarang dan memperoleh data tentang keberadaan dan perkembangan Musik Gambang Semarang. Penelitian ini dilakukan di Kota Semarang, tepatnya di Grup Gambang Semarang "Pahat Ethnic". Penelitian ini menggunakan metode kualitatif dan data dikumpulkan melalui proses observasi, wawancara dan studi pustaka. Hasil penelitian menunjukkan bahwa dalam grup "Pahat Ethnic", Musik Gambang Semarang masih dikelola dengan baik oleh remaja yang merupakan anggota dari Grup Pahat Ethnic dan masih disukai oleh masyarakat Kota Semarang dan sekitarnya. Gambang Semarang terus bertahan dan tumbuh dalam hal alat musik, komposisi, pemain dan fungsi mereka.
\end{abstract}

Kata kunci: gambang semarang, keberadaan musik gambang, budaya semarangan

\begin{abstract}
The objective of the research is to know the existence of music Gambang Semarang in Semarang City and obtain data about the existence and development of the Gambang Semarang Music. This research was conducted in the city of Semarang, precisely in the Gambang Semarang Group "Pahat Ethnic". This is study used qualitative methods and the data area collected through observation, interview and library study. The results showed that in "Pahat Ethnic", Gambang Semarang is still maintained by young people who are members of the Pahat Ethnic group and are still favored by the Semarangan community. Gambang Semarang continues to survive and to grow up in terms of musical instruments, composition, players and their functions.
\end{abstract}

Keywords: gambang semarang, existance of music gambang, semarangan culture 


\section{Pendahuluan}

Kebudayaan di Indonesia sangat melekat pada semua masyarakat tanah air yang sudah lama menetap di Indonesia. Keselarasan budaya membuat masyarakat semakin luas mengetahui perbedaan-perbedaan berbagai macam ragam budaya di berbagai daerah. Mulai dari kebiasaan, adat istiadat, seni budaya, hingga ciri khas makanan setiap budaya. Tetapi, semakin berkembangnya era globalisasi yang sangat kuat membuat masyarakat seakan-akan lupa dan tidak tahu ragam budaya di negaranya sendiri. Budaya masyarakat barat yang semakin melekat membuat kebiasan menjadi berubah dan berlomba-lomba ingin disebut masyarakat modern atau juga kebarat-baratan.

Tanpa disadari masyarakat banyak meninggalkan nilai-nilai budaya bangsa sendiri, padahal bangsa akan maju oleh dasar-dasar kebudayaan yang dimiliki, seperti masyarakat Bali, yang benar-benar memanfaatkan budayanya sebagai media untuk memajukan dan meningkatkan derajat masyarakatnya sendiri.

Keberadaan budaya Indonesia memiliki keragaman yang penuh makna, nilai, kualitas artistik serta berbagai muatan lokal lainnya. Kebudayaan Indonesia terbentuk salah satunya dari berbagai akibat penjajahan, perdagangan, misionaris, dan sebagainya. Perkembangan teknologi dan derasnya arus informasi yang mudah diperoleh dapat menggeser minat masyarakat terutama kalangan muda terhadap kesenian tradisional sehingga tidak mengherankan bila suatu saat seni tradisi lisan ada akhirnya akan dapat punah.

Salah satu wilayah di Indonesia yang memiliki keragaman dan kekayaan budaya tersaebut adalah Semarang. Semarang memiliki banyak kekayaan seni budaya. Di antaranya Gambang Semarang, Tari Semarangan, dan Warak Ngendog. Beberapa bentuk seni tersebut masih dapat dijumpai hingga kini dalam masrayakat Semarang. Tetapi sangat disayangkan, kekayaan ini mulai tidak mendapat tempat di hati masyarakat bila dilihat pertunjukan seni yang bernuansa Semarangan sudah jarang terlihat. Buktinya kesenian Gambang Semarang, Tari Semarangan, dan Warak Ngendog jarang dimainkan oleh kawula muda Semarang saat ini. Maka tampaknya lebih menyukai musik-musik Barat. Kesenian Gambang Semarang, Tari Semarangan, dan Warak Ngendog, sebagai aset negeri yang bernilai tinggi, perlulah dipertahankan kelestariannya. Selain itu, juga perlu dilakukan kajian dan penggalian yang matang akan nilai-nilai positif yang dimilikinya.

Kemungkinan hal ini disebabkan langkanya kajian terhadap seni Semarangan, sehingga para generasi muda Semarang tidak memiliki bekal mengenal nilai-nilai positif yang dimiliki seni Semarangan tersebut. Sementara pengaruh seni dari luar terus masuk, akibatnya mereka lebih tertarik dan mencintai seni dan budaya yang datang dari luar wilayah Semarang.

Gambang Semarang merupakan kesenian tradisional yang terdiri atas seni musik, vokal, tari, dan lawak. Dalam perkembangannya lagu-lagu Gambang Semarang terasa gembira dan menyatu dengan tari, gemulai namun tetap segar. Karakteristiknya terletak pada gerak lincah dan dinamis yang diiringi dengan alunan musik. Jenis instrumen musiknya seperti bonang, gambang, gong suwuk, kempul, saron, demung, kendang dan ketipung (www.smkn.org/isi/gambang). Musik Gambang Semarang juga tidak lagi murni mengiringi lagu-lagu sarat dengan pantun, seperti kincir-kincir, gambang semarang, impian semalam, dan malu-malu kucing. Gambang Semarang berubah menjadi campursari dan pop (www.pikiranrakyat.com/cetak/0303/16/6/07). 
Kesenian Gambang Semarang merupakan hasil persebaran budaya Betawi di Jakarta yang dibawa sejumlah orang Betawi yang bermigrasi dan bermukim di tengah Kota Semarang. Untuk itu penulis mencoba mengangkat kelompok Kesenian Gambang Semarang "Pahat Ethnic" sebagai objek penelitian ini.

\section{Metode}

Penelitian ini menggunakan pendekatan kualitatif naturalistik, untuk mengetahui aktualitas, realitas dan persepsi manusia melalui pengakuan mereka yang mungkin tidak dapat diungkap melalui penonjolan pengukuran formal atau pertanyaan penelitian yang telah dipersiapkan terlebih dahulu. Sasaran utama penelitian ini adalah Grup Musik Gambang Semarang "Pahat Ethnic" Kota Semarang. Untuk memperoleh data yang diperlukan dalam penelitian ini, cara yang dilakukan peneliti adalah melakukan observasi, wawancara, dan dokumentasi. Analisis data dibagi menjadi tiga tahapan, antara lain reduksi data, sintesisasi, dan penarikan kesimpulan/verifikasi.

\section{Hasil dan Pembahasan}

\section{Perkembangan Seni Gambang di Indonesia}

Sejak awal di Indonesia orkes atau seni gambang (sebelum Gambang Kromong dan Gambang Semarang) sudah berfungsi sebagai hiburan, walaupun dalam perkembangannya pada zaman dahulu orkes ini mempunyai bentuk maupun penggemar yang berubah-ubah. Menurut Phoa Kian Sioe, bahwa orkes ini semula dimainkan dengan lebih teratur sehingga terkesan formal. Para pemainnya harus menguasai not-notnya yang ditulis dengan menggunakan huruf-huruf Tionghoa, dan memainkannya dengan membaca not dan secara halus dan lembut (Sioe, 1949, p. 37).

Permainan Orkes Gambang ini seperti musik klasik atau musik jazz pada zaman sekarang, dan para pemainnya harus benar-benar menguasai not, lagu, dan peralatannya. Semula orkes gambang memang hanya untuk mengiringi penyanyi yang disebut Cio Kek, dan tidak untuk tarian. Para penyanyi atau Cio Kek itu harus orang-orang pilihan, wanita-wanita cantik dan bagus suaranya. Kondisi ini telah menyebabkan orkes gambang mempunyai gengsi sosial yang cukup tinggi, karena akhirnya para pejabat atau orang-orang kaya berlombalomba untuk mempunyai orkes ini beserta para pemain handal dan Cio Kek pilihannya. Mereka mendirikan gedung-gedung khusus untuk tempat orkes ini, sebagai tempat hiburan yang bergengsi (Sioe, 1949, p. 38).

Sejalan dengan perkembangan orkes gambang menjadi orkes Gambang Kromong, kesenian ini juga semakin digemari oleh orang dan memuncak ketenarannya. Pada jaman dahulu di samping dipentaskan di gedung-gedung milik hartawan, Gambang Kromong sering ditampilkan untuk pesta-pesta pernikahan dan untuk memeriahkan tahun baru China sampai Cap Go Meh. Namun setelah itu lambat laun kedudukan orkes Gambang Kromong kian surut di mata masyarakat, karena semakin kurang profesional.

Kemudian Gambang Kromong dibawa ke Semarang yang diberi nama Gambang Semarang. Semula kesenian ini di Semarang juga tampak lebih memasyarakat pada kalangan tertentu, walaupun akhirnya juga merakyat dan lambat laun menghilang. Kesenian ini muncul lagi pada tahun 1960-1980 kemudian menghilang lagi (Puguh, 2000: 64). Meskipun musik Gambang Semarang merupakan adaptasi dari musik Gambang Kromong tetapi Gambang Semarang memiliki karakteristiknya sendiri. Karakterisitik tersebut meliputi alat musik yang mengalami penambahan dan perkembangan, tarian dan lagu yang khas Semarang serta 
pemain yang merupakan campuran antara orang pribumi dan Cina. Merujuk pada hal tersebut dapat dikatakan bahwa karakteristik dari Gambang Semarang banyak dipengaruhi oleh kebudayaan Cina. Alat musik yang digunakan adalah perpaduan antara alat musik Jawa yakni gamelan dan alat musik gesek yang berasal dari Cina yaitu Tehyan, Konghayan, dan Sukong. Selain itu dalam pertunjukan Gambang Semarang terdapat penyanyi dan penari sebagai pelengkap (WINANGSIT, Ganap, \& Erimurti, 2017, p. 62).

\section{Gambang Semarang pada Kelompok Pahat Ethnic Semarang}

Sampai saat ini asal usul kesenian Gambang Semarang masih diperdebatkan. Banyak orang mengatakan bahwa Gambang Semarang adalah kesenian impor dari Betawi, karena memang dahulu alat-alat musiknya pernah dibeli dari Jakarta dan tidak berbeda dengan alatalat musik Gambang Kromong yang terdiri atas gambang, Kromong untuk sebutan di Betawi sedangkan bonang untuk penyebutan di Semarang, suling, kendang, gong, siter, demung, saron, kempul, kecrek, alat gesek yaitu tehyan, kongahyan, dan sukong (hasil wawancara dengan Supiyanto yang merupakan generasi penerus Gambang Semarang, Semarang 13 Maret 2018). Akan tetapi, adapun suatu pernyataan bahwa Kesenian Gambang Kromong justru berasal dari Semarang. Kesenian ini dibawa oleh para imigram Cina yang langsung Semarang. Di sini mereka mengembangkan kesenian yang dikenal dengan Gambang Semarang (Gunawijaya, 1996: 30). Berdasarkan penelitian ini ternyata masing-masing pernyataan memiliki dasar historis.

Betapa kesenian ini, sehingga dalam tahun 1940 tercipta suatu lagu dengan judul Gambang Semarang. Lagu tersebut tercipta atas kerjasama antara Oei Yok Siang, pembuat lagu, dan Sidik Pramono, penulis syair lagu. Kedua seniman ini bertempat tinggal di Magelang. Sidik Pramono adalah pemain orkes Perindu di Magelang. Pada tahun yang sama lagu Gambang Semarang telah disiarkan pertama kali oleh orkes Perindu di studio Laskar Rakyat Magelang dengan biduanita Nyi Ertinah (Budiman, 1975: 43).

Syair lagu Gambang Semarang dapat dipahami sebagai kesaksian dan ekspresi perasaan terkesan akan nilai estetis yang ditampilan oleh kesenian Gambang Semarang. Di samping Igu Gambang Semarang, Oei Yok Siang juga menciptakan lagu-lagu lain yang cocok dengan iringan musik Gambang Semarang seperti Aksi Kucing dan Impian Semalam.

\section{Karakteristik Gambang Semarang Kelompok Pahat Ethnic}

Konsep estetis dalam Gambang Semarang meliputi musik, nyanyian, tarian, lawak, dan sastra (pantun). Dengan kata lain, Gambang Semarang tidak hanya merupakan pertunjukan musik karena di dalam juga terdapat unsur nyanyian, tarian, lawak, dan pantun yang dinyanyikan secara bergantian (berbalas pantun).

Instrumen musik yang digunakan dalam garapan musik Gambang Semarang pada umumnya, meliputi : 1) Gambang; 2) Bonang; 3) Kendang (membranophone); 4) Kempul dan Gong; 5) Suling/Flute; 6) Kecrek/Tamborine; 7) Demung; 8) Saron; 9) Konghayan. Namun berbeda di "tangan" remaja-remaja berdomisili Semarang yang tergabung dalam kelompok kesenian Gambang Semarang "Pahat Ethnic". Remaja-remaja ini memberikan "sentuhan" yang berbeda di garapan musik Gambang Semarang. Dalam penyajiannya, selain Gambang Semarang, juga menyajikan berbagai warna musik seperti jazz, keroncong, dangdut, campursari, lagu barat, dan lagu mandarin. Pada masa pengelolaannya, Gambang Semarang mengalami inovasi dalam berbagai aspek musiknya. Instrumen musik yang dilengkapi dengan bass, saxophone, biola, keyboard, dan drum. Dengan demikian dalam nyanyiannya juga ikut 
berkembang. Pada saat itu dalam kesenian Gambang Semarang di nyanyikan juga lagu-lagu Barat dan Mandarin.

Haryati Soebadio mengartikan bahwa identitas budaya sebagai kepribadian budaya suatu bangsa, atau lebih dikenal dengan istilah local genius. Local genius adalah kemampuan untuk melakukan transformasi, seleksi, inovasi, adaptasi, akulturasi, serta toleransi terhadap berbagai pengaruh budaya luar (asing) untuk mewujudkan budaya yang berkarakter dan sesuai dengan kebutuhannya (Maestro \& Sinaga, 2018). Istilah local genius merupakan konsep yang sering digunakan arkeolog untuk menjelaskan adanya unsur tradisional yang mampu bertahan dan mengakomodasi unsur budaya dari luar dan mengintegrasikan dalam kebudayaan asli (Sinaga, 2016, p. 94).

Selain instrumen musik, Kesenian Gambang Semarang juga memiliki unsur lainnya yang mengindahkan garapan musik Gambang Semarang, yaitu Lagu. Adapun lagu-lagu pokok dalam musik Gambang Semarang, sebagai berikut:

\section{Lagu-lagu dalam Gambang Semarang}

\begin{tabular}{|c|c|c|c|}
\hline No & Judul Lagu & Pencipta & Makna \\
\hline 1 & $\begin{array}{l}\text { Gambang } \\
\text { Semarang/Empat } \\
\text { Penari }\end{array}$ & Oey Yok Siang & $\begin{array}{l}\text { Kelincahan dan gerak-gerik penari } \\
\text { Gambang Semarang }\end{array}$ \\
\hline 2 & $\begin{array}{l}\text { Gado-gado } \\
\text { Semarang }\end{array}$ & Kelly Puspito & $\begin{array}{l}\text { Sejarah, kondisi geografis, etnis, dan } \\
\text { budaya Kota Semarang }\end{array}$ \\
\hline 3 & Simpang Lima & Kho Tjai Hian & $\begin{array}{l}\text { Keindahan sebuah kawasan di Kota } \\
\text { Semarang yang sangat terkenal yaitu } \\
\text { Simpang Lima }\end{array}$ \\
\hline 4 & $\begin{array}{l}\text { Semarang Tempo } \\
\text { Doeloe }\end{array}$ & Jayadi & $\begin{array}{l}\text { Ekspresi keprihatinan dan sindiran } \\
\text { terhadap kondisi bangunan kuni di Kota } \\
\text { Semarang }\end{array}$ \\
\hline 5 & Tanjung Emas & Kelly Puspito & $\begin{array}{l}\text { Kemegahan mercusuar dan berbagai } \\
\text { kegiatan di pelabuhan Semarang dengan } \\
\text { kapal-kapal yang sedang berlabuh }\end{array}$ \\
\hline
\end{tabular}

Sumber: Wawancara dengan Supiyanto, Semarang 25 Maret 2018 
Dalam pertunjukan Kesenian Gambang Semarang, tidak hanya musik yang dominan. Namun juga ada unsur seni lain, yaitu seni tari. Tarian di dalam Kesenian Gambang Semarang berpijak pada gerak dasar tari Gambang Semarang yaitu ngondek, ngeyek, dan genjot. Dipadu dengan unsur dan ragam gerak tari putri Jawa Klasik gaya Surakarta yang sudah memasyarakat di Kota Semarang.

Selain tarian juga ada lawak. Ada tiga jenis lawakan yang terdapat dalam pertunjukan lawak Gambang Semarang. Ketiga jenis lawakan itu adalah: a) Lawakan verbal yaitu lawakan dengan menggunakan monolog atau dialog; b) Lawakan non-verbal yaitu lawakan dengan menggunakan gerak-gerik yang menimbulkan kelucuan atau comedy of manners; dan c) Lawakan musikal yaitu lawakan yang memanfaatkan instrumen musik sebagai pengiring dan pendukung suasana kocak.

Gambang Semarang dalam perkembangannya memang tidak seberuntung dengan seni pertunjukan rebana yang merupakan folklor akulturasi dengan Timur Tengah. Hal ini disebabkan karena Gambang Semarang merupakan folklor akulturasi dengan kesenian Cina. Menurut Soedarsono, pada jaman sekarang secara garis besar seni pertunjukan dalam hal ini Seni Gambang berguna: (1) sebagai sarana upacara, (2) sebagai hiburan pribadi, (3) sebagai tontonan. Pada jaman dahulu kesenian tradisional ini cenderung berfungsi ritual, walaupun lambat laun sejalan dengan bergesernya waktu terjadi perubahan untuk kepentingan hiburan pribadi dan tontonan publik, serta dapat tumpang tindih. Dalam hal ini, selain fungsinya, ada yang bentuknya juga berubah, namun ada pula yang tidak banyak berubah (Sudarsono, 2002).

\section{Tinjauan Gambang Semarang dalam Sosial dan Budaya}

Mengamati aktivitas seni pertunjukan Gambang Semarang dalam masyarakat tidak lepas dari peran, fungsi, dan kedudukannya. Gambang Semarang yang berperan aktif dalam komunitas tertentu serta digemari oleh masyarakat di wilayah Semarang dan sekitarnya masih belum mampu sepenuhnya berperan sebagai satu pertunjukan tunggal atau berdiri sendiri seperti halnya genre musikal lainnya. Peran tersebut masih sebatas sebagai pendukung serta pelengkap suatu hajat dalam acara pribadi (private), komunal, atau nasional seperti pengukuhan gelar Profesor dalam akademika, penerimaan tamu kenegaraan (kedinasan) dan hajat pernikahan orang-orang penting (dibaca pejabat).

Terciptanya rasa kebersamaan, keberadaan seni pertunjukan Gambang Semarang dapat pula berperan sebagai salah satu sarana meningkatkan jalinan persahabatan dan kesatuan diantara anggota pemain Gambang Semarang, penggemar, serta masyarakat pendukungnya. Peran ini dapat tercermin atas keberadaannya latihan rutin. Pada saat latihan senantiasa dihadiri oleh masyarakat tertentu dan penggemar serta penikmat Gambang Semarang.

Tidak dapat dipungkiti bahwa keberlangsungan serta niat latihan maupun pementasan ini akan menghadirkan suasana negosiatif dengan berbagai permasalahan pribadi maupun kelompok, diantaranya terjadi negosiasi bisnis maupun jalinan tali asmara. Dengan menyoroti adanya pementasan Gambang Semarang dalam masyarakat, pada umumnya pengelolaannya dilakukan oleh instansi, lembaga, atau pribadi yang menyumbangkan dana, hal ini dikarenakan biaya latihan dan sekali tampil memerlukan biaya yang cukup besar dan kurang praktis. Selain mempunyai suatu peran yang penting guna memanfaatkan folklor, namun tampak pula dijadikan suatu prestis, hal ini tercermin bahwa masyarakat yang nanggap atau menyewa adalah masyarakat kalangan menegah keatas yang menunjukkan lambang kesejahteraan, dan kebanggaan status sosial. 
Gambang Semarang sebagai folklor juga mengalami berbagai tantangan dan tekanantekanan baik dari luar maupun dalam. Tekanan dari dari luar terhadap folklor ini dapat dilihat dari pengaruh berbagai karya-karya kesenian populer dan juga karya-karya kesenian yang lebih modern atau sering disebut dengan budaya pop. Kesenian-kesenian populer tersebut lebih mempunyai keleluasaan dan kemudahan kemudahan dalam berbagai komunikasi baik secara alamiah maupun teknologi juga praktis serta murah, sehingga hal ini memberikan pengaruh terhadap masyarakat. Selain itu, aparat pemerintah nampaknya lebih mengutaman atau memprioritaskan segi keuntungan ekonomi (bisnis) ketimbang segi sosial budayanya, sehingga kesenian rakyat semakin tertekan lagi.

Segi komersialisasi yang dilakukan oleh aparat pemerintah ini tentu saja didasarkan atas pemikiran yang pragmatis dan cenderung mengikuti perkembangan-perkembangan dan perubahan-perubahan yang ada. Dengan demikian, pengaruh ini jelas-jelas mempunyai dampak yang besar terhadap perkembangan kreatifitas folklor itu sendiri. Di pihak lain, adanya masyarakat yang masih setia kepada tradisinya perlahan-lahan mengikuti perkembangan pembangunan.

Pada umumnya folklor terutama Gambang Semarang sulit untuk bangun lagi karena kerasnya daya saing dengan kesenian kesenian yang sangat modern. Sementara itu pemerintah hampir tidak peduli lagi dengan adanya folklor yang ada di daerahnya. Hal ini, bisa saja disebabkan oleh adanya asumsi-asumsi yang dikaitkan dengan konsep-konsep dasar pembangunan di bidang kesenian yang penekanannya dan intinya melestarikan dan mengembangkan kesenian yang bertaraf kecenderungan universal. Sehingga, keseniankesenian yang ada sekarang ini dapat dianggap tidak sesuai dengan objek-objek dan tujuan dari pembanguan yang sedang dijalaninya ini. Dengan kata lain, bahwa keaslian dari suatu kesenian dipandang belum dapat dibanggakan sebagai bukti keberhasilan suatu pembangunan didaerahnya. Untuk menuju kepada tindakan pengembangan dan pemanfaatan Gambang Semarang ini harus ada upaya atau perbaikan-perbaikan yang perlu diperhatikan agar kemasan folklor bangsa Indonesia dapat diterima dan berkembang secara global, walaupun tetap mengacu kepada kekuatan nilai-nilai asli/lokal.

Pada pengamatan yang lebih sempit dapat kita melihat tingkah laku aparat pemerintah dalam menangani perkembangan folklor, dimana banyak campur tangan dalam menentukan objek dan berusaha merubah agar sesuai dengan tuntutan pembangunan. Dalam kondisi seperti ini arti dari Gambang Semarang sebagai folklor menjadi hambar dan tidak ada rasa seninya lagi. Melihat kecenderungan tersebut, maka penulis melihat aparat pemerintah telah menjadikan para seniman dipandang sebagai objek pembangunan dan diminta untuk menyesuaikan diri dengan tuntutan simbol-simbol pembangunan.

Hal ini tentu saja mengabaikan masalah pemeliharaan dan pengembangan kesenian secara murni, dalam arti benar-benar didukung oleh nilai seni yang mendalam dan bukan sekedar hanya dijadikan model saja dalam pembangunan. Hal itu menjadikan Gambang Semarang semakin lama tidak mempunyai ruang yang cukup memadai untuk perkembangan secara alami atau natural, karena itu secara tidak langsung Gambang Semarang akhirnya menjadi sangat tergantung oleh model-model pembangunan yang cenderung lebih modern dan rasional. Memang diakui bahwa Gambang Semarang saat ini membutuhkan dana dan bantuan pemerintah sehingga sulit untuk menghindari keterlibatan pemerintah dan bagi para seniman rakyat ini merupakan sesuatu yang sulit pula membuat keputusan sendiri untuk sesuai dengan keaslian (originalitas) yang diinginkan para seniman rakyat tersebut. Oleh 
karena itu pemerintah harus menjalankan dengan benar-benar peranannya sebagai pengayom yang melindungi keaslian dan perkembangan secara estetis kesenian rakyat tersebut tanpa harus merubah dan menyesuaikan dengan kebijakan-kebijakan politik.

Globalisasi budaya yang begitu pesat harus diantisipasi dengan memperkuat identitas kebudayaan nasional. Berbagai folklor yang sesungguhnya menjadi aset kekayaan kebudayaan nasional jangan sampai hanya menjadi alat atau slogan para pemegang kebijaksanaan, khususnya pemerintah, dalam rangka keperluan turisme, politik dan sebagainya. Selama ini pembinaan dan pengembangan folklor yang dilakukan lembaga pemerintah masih sebatas pada unsur formalitas belaka, tanpa menyentuh esensi kehidupan kesenian yang bersangkutan. Akibatnya, folklor tersebut bukannya berkembang dan lestari, namun justru semakin dijauhi masyarakat. Dengan demikian, tantangan yang dihadapi Gambang Semarang cukup berat. Karena pada era teknologi dan komunikasi yang sangat canggih dan modern ini masyarakat dihadapkan kepada banyaknya alternatif sebagai pilihan, baik dalam menentukan kualitas, selera maupun budget. Hal ini sangat memungkinkan keberadaan dan eksistensi Gambang Semarang dapat dipandang dengan sebelah mata oleh masyarakat, jika dibandingkan dengan kesenian modern yang merupakan imbas dari budaya pop.

Dalam menghadapi hal-hal tersebut, terdapat beberapa alternatif untuk mengatasinya, yaitu meningkatkan Sumber Daya Manusia (SDM) bagi para seniman tradisional. Selain itu, mengembalikan peran aparat pemerintah sebagai pengayom dan pelindung, dan bukan sebaliknya justru menghancurkannya demi kekuasaan dan pembangunan yang berorientasi pada dana-dana proyek atau dana-dana untuk pembangunan dalam bidang ekonomi saja.

\section{Kesimpulan}

Gambang Semarang merupakan warisan budaya yang masih eksis meskipun keadaannya ibarat hidup segan mati tak mau dari tahun 1990-an, hal tersebut disebabkan karena adanya pergeseran nilai kesenian tradisional Gambang Semarang dari kesenian rakyat menjadi kesenian elit yang menjadikan masyarakat kurang begitu mengenal selain karena faktor historis. Meskipun sudah ada upaya dari pemerintah untuk membangkitkan kembali Gambang Semarang dengan berbagai aspek, namun demikian dari aspek revitalisasi budaya masih banyak yang perlu diprioritaskan, terutama dalam rangka melestarikan dan memanfaatkan Gambang Semarang.

Sesuai dengan keinginan dari masyarakat agar kesenian Gambang Semarang dapat terus dipertahankan, maka diperlukan campur tangan pemerintah. Dalam hal ini pemerintah daerah untuk membantu usaha ini dengan langkah-langkah konkret. Pemerintah Daerah dapat menyediakan sarana dan prasarana dalam rangka pelestarian budaya, serta mengadakan kegiatan rutin untuk pemuda yang bersifat kompetitif untuk mencari bibit baru atau generasi baru sebagai seniman Gambang Semarang. 


\section{References}

Budiman, Amin. 1975. Semarang Sepanjang Jalan Kenangan. Kerjasama PEMDA DATI II Semarang, Dewan Kesenian Jawa Tengah dan Aktor Studio Semarang.

Gunawijaya, Jajang dan Solihin, Asep. 1996. "Perkembangan Gambang Kromong". Proyek Pelestarian dan Pengembangan Kesenian Tradisional Betawi. Dinas Kebudayaan DKI Jakarta: Jakarta.

Puguh, Respati Dhanang. 2000. Laporan Terpadu Penelitian Hibah Bersaing Perguruan Tinggi Penataan Kesenian Gambang Semarang Sebagai Identitas Budaya Semarang. Departemen Pendidikan Nasional Universitas Diponegoro: Semarang.

Soedarsono. 1989. Seni Pertunjukan Jawa Tradisional dan Pariwasata Daerah Istimewa Yogyakarta. Departemen Pendidikan dan Kebudayaan Yogyakarta.

Maestro, E., \& Sinaga, F. S. S. (2018). Kearifan Lokal Lagu Ayam Den Lapeh Garapan Orkes Gumarang.

Sinaga, F. S. S. (2016). Musik Trunthung Sebagai Media Ekspresi Masyarakat Warangan. In Seminar Antar Bangsa (pp. 161-174). INA-Rxiv. https://doi.org/10.31227/osf.io/wc4vy

Sioe, P. K. (1949). Orkest gambang, hasil kesenian Tionghoa Peranakan di Djakarta. Pantja Warna, 1(9), 37-39.

Sudarsono. (2002). Seni pertunjukan Indonesia di era globalisasi. Gadjah mada University Press.

WINANGSIT, E., Ganap, V., \& Erimurti, K. (2017). MUSIK GAMBANG SEMARANG GARAPAN PAGUYUBAN KESENIAN OTTY PANOEDJOE DI BALEMONG RESORT UNGARAN. Universitas Gadjah Mada.

www.pikiranrakyat.com/cetak/0303/16/6/07 (Diakses tanggal 1 Juni 2018) 